\title{
Knowledge, attitude and practice regarding generic drugs and branded drugs: a cross sectional study
}

\author{
Gyanendra Kumar, Aditi Garg*, Jatinder Kaur Dhillon, \\ Arshad Eranhikkal, Manjakandi Smitha
}

Department of Pedodontics and Preventive Dentistry, Maulana Azad Institute of Dental Sciences, New Delhi, India

Received: 23 June 2019

Accepted: 31 July 2019

\section{*Correspondence to:}

Dr. Aditi Garg,

Email: aditigarg24.3@

gmail.com

Copyright: (C) the author(s), publisher and licensee Medip Academy. This is an openaccess article distributed under the terms of the Creative Commons Attribution NonCommercial License, which permits unrestricted noncommercial use, distribution, and reproduction in any medium, provided the original work is properly cited.

\begin{abstract}
Background: Medicines play a main role in the process of human development. The rational utilization of medicines can decrease morbidity and mortality as well as improve quality of life. In an era of steeply rising health care expenses, generic medicines provide a less expensive alternative to branded medicines. Use of generic drugs can contribute to substantial savings in medicines expenditure and the issue of access and affordability is thus addressed.

Methods: A sample of 500 patients selected from out patient department was randomly selected. A self-instructed questionnaire was used for the study for the duration of 1 month. Data was analyzed using IBM SPSS statistics Version 20 New York, United States. Summary statistics were expressed using mean and standard deviation (SD) for numerical variables (median and interquartile ranges [IQRs] when skewed) and counts and percentages for categorical variables.

Results: Participants reported with $17.23 \%$ knowledge score, $40.65 \%$ attitude score, and $7.96 \%$ attitude score.

Conclusions: In the study it was found that there is significant correlation between knowledge and attitude whereas no correlation was found between knowledge and practice regarding usage of generic drugs.
\end{abstract}

Keywords: Branded drugs, Generic drugs, Non-proprietary, Proprietary, Multinational companies, Prescriptions

\section{INTRODUCTION}

Medicines play a main role in the process of human development. The rational utilization of medicines can decrease morbidity and mortality as well as improve quality of life. Medicine pricing is the most crucial element which restricts access to medicines. ${ }^{1}$ The steep increase of health care expenditures is one of the biggest problems faced by most of the countries. Affordability of medicines and increased costs has become a major challenge for both governments and patients. In an era of steeply rising health care expenses, generic medicines provide a less expensive alternative to branded medicines. Use of generic drugs can contribute to substantial savings in medicines expenditure and the issue of access and affordability is thus addressed. ${ }^{2}$ In order to promote the use of cheaper generic medicines, a generic substitution policy has been implemented in many of the world's developed and developing countries.

A generic drug is bioequivalent or identical to a brand name drug in dosage form, route of administration, quality, performance characteristics, safety, strength, and intended use. On expiration of the original product's patent term protection, other manufacturing companies 
may file submissions to Government/regulatory authorities for approval to market generic versions of the original medicine. Generic drugs may be marketed under the non-propriety name or as a branded generic. Branded generic drugs have names derived from a combination of the manufacturers name and the non-proprietary name. This enables the manufacturer to market the product in a way similar to the proprietary product. ${ }^{3}$ Generic drugs are cheaper in comparison to branded drugs because there is no need to make investments in research and development as in the case of new drugs. The prevailing fierce competition in drug industry also makes the manufacturers keep to low prices. Currently, fast moving branded medicines are manufactured by multinational companies or large Indian companies. ${ }^{4}$ The branded medicines are usually expensive as they are strongly promoted through doctors and chemists and such promotional costs add to their retail prices. The practice of bribing doctors by pharmaceutical companies to create more and more prescriptions is not recent in the country as well as world over. The unethical promotional practices being adopted by the companies make the essential medicines unaffordable to common man.

One of the many ways to control healthcare expenditure is to promote the use of cheaper generic drugs instead of the more expensive branded equivalents. While manufacturing generic drugs, the drug companies use the same active ingredients and are shown to work the same way in the body, they have the same risks and benefits as their brand name counterparts. Both branded and generic drugs are manufactured by conforming to International standards. Brand name drugs are usually given patent protection for 20 years from the date of submission of the patent. There are only rare circumstances where substituting a generic drug for a brand name product (or vice versa) may not be appropriate for a particular patient. For some patients, generic substitution may be inappropriate due to reactions to inactive ingredients or problems with the pill shape, color or related characteristics. ${ }^{5}$ Patients should become assertive and insist upon the doctors to prescribe generic drugs if available, so that the patient would get the product at the best possible price. Thus if generic drugs are bought by the patient, the patient may not lose money by going in for branded drugs, which are too costly. The essential drug concept adopted in many developing countries promotes use of generic medicines, the main reason for generics is drug containment through competition to improve access to essential medicines.

The scientific data regarding experience and attitude of patients and general public towards generic drugs is necessary for sustaining a generic drug use policy but have been explored to a limited extent. Reports on patient attitudes and preferences are mostly available from countries where generic drug substitution in retail pharmacies is an accepted practice, unlike in India. ${ }^{7} \mathrm{We}$, therefore, undertook this study to evaluate the experiences and attitudes of patients towards generic drugs comparing the same with the experience regarding branded medicines purchased from retail medicine shops.

\section{METHODS}

A questionnaire-based cross-sectional study was conducted among patients attending Out Patient Department of Maulana Azad Institute of Dental Sciences. 500 Participants seeking dental treatment and those who were accompanying the patient were both included in the study and the sample selection was done using random sampling technique. A self-instructed questionnaire was used for the study for the duration of 1 month from $1^{\text {st }}$ February 2019 to $28^{\text {th }}$ February 2019.

The questionnaire consisted of two parts. The first part captured data pertaining to the demographic details including name, age, sex, occupation, income and socioeconomic status. The second part consisted of twenty structured closed-ended items assessing the knowledge, attitude and practice toward generic and branded drug usage. For each item in part 2 of the survey, we used an additive valuation scale (Likert type). Each item is presented as a positive closed statement followed by different answer options that indicate different agreement or disagreement levels (from strongly agree to strongly disagree). To each answer a specific grade is given (from 1 to 5), being able then to calculate the total result by adding the grade of each item if needed.

Data were analyzed using IBM SPSS statistics Version 20 New York, United States. Summary statistics were expressed using mean and standard deviation (SD) for numerical variables (median and interquartile ranges [IQRs] when skewed) and counts and percentages for categorical variables. Correlation was analyzed between knowledge, attitude and practice related to generic and brand name drugs. Correlation was made with each of these components with gender, education, income, occupation and socio economic status.

\section{RESULTS}

A survey conducted among 500 patients, out of which $56.4 \%$ males and $43.6 \%$ females participated in the study. The mean age of the participants was $35.76 \pm 8.82$ years. Of the total sample, majority of the population was unemployed, with only $0.6 \%$ with occupation of senior executives. Maximum number of participants had income less than 1520 Rs. and around $25.4 \%$ had income between 1521-4555 Rs. Nearly $41.4 \%$ were high school certified whereas, only $0.6 \%$ of professors or honors participated in the study. The demographic data is as shown in Table 1.

In this study the mean knowledge score was $17.23 \pm 3.620$ where participants stated that they know what a generic medicine is. Out of this, $3.21 \%$ know that generic drugs are cheaper than branded drugs. Nearly $3.34 \%$ believe that medicines that have been longer in the market are safer than newer drugs. Also, 3.67\% know that generic 
drugs are less expensive whereas only $3.01 \%$ of them agree that generic drugs are more effective than brand name drugs as shown in Table 2.

Table 1: Demographic data of patients.

\begin{tabular}{|c|c|c|}
\hline Characteristics & $\mathbf{N}$ & $\%$ \\
\hline \multicolumn{3}{|l|}{ Sex } \\
\hline Males & 282 & 56.4 \\
\hline Females & 218 & 43.6 \\
\hline \multicolumn{3}{|l|}{ Educational status } \\
\hline Illiterate & 6 & 1.2 \\
\hline Primary school certificate & 9 & 1.8 \\
\hline Middle schol certificate & 36 & 7.2 \\
\hline High schol certificate & 207 & 41.4 \\
\hline Intermediate or diploma & 24 & 4.8 \\
\hline Intermediate or diploma & 24 & 4.8 \\
\hline Graduate & 167 & 33.4 \\
\hline Profession or honours & 51 & 10.2 \\
\hline \multicolumn{3}{|l|}{ Occupation } \\
\hline Unemployed & 177 & 35.4 \\
\hline Elementary occupation & 77 & 15.4 \\
\hline $\begin{array}{l}\text { Plants and machine operators and } \\
\text { assemblers }\end{array}$ & 6 & 1.2 \\
\hline Craft and related trade workers & 45 & 9.0 \\
\hline $\begin{array}{l}\text { Skilled agricultural and fishery } \\
\text { workers }\end{array}$ & 21 & 4.2 \\
\hline $\begin{array}{l}\text { Skilled workers and shop and } \\
\text { market sales workers }\end{array}$ & 44 & 8.8 \\
\hline Clerks & 30 & 6.0 \\
\hline $\begin{array}{l}\text { Techniques and associate } \\
\text { professionals }\end{array}$ & 9 & 1.8 \\
\hline Professionals & 67 & 13.4 \\
\hline $\begin{array}{l}\text { Legislatures, senior officials and } \\
\text { managers }\end{array}$ & 21 & 4.2 \\
\hline \multicolumn{3}{|l|}{ Income (in Rs.) } \\
\hline Less than equal to 1520 & 171 & 34.2 \\
\hline $1521-4555$ & 127 & 25.4 \\
\hline $4556-7593$ & 78 & 15.6 \\
\hline 7594-11361 & 52 & 10.4 \\
\hline $11362-15187$ & 60 & 12.0 \\
\hline $15188-30374$ & 12 & 2.4 \\
\hline \multicolumn{3}{|c|}{ Kuppuswamy's socioeconomic status scale 2018} \\
\hline Upper middle & 275 & 55.0 \\
\hline Lower middle (III) & 93 & 18.6 \\
\hline Upper lower & 120 & 24.0 \\
\hline Lower $(\mathrm{V})$ & 12 & 2.4 \\
\hline
\end{tabular}

The mean attitude score was found to be $40.65 \pm 6.448$. Out of these $3.30 \%$ stated that they would like to take a generic drug than a branded drug, $3.97 \%$ participants feel the need to switch from branded drugs to generic ones. Around $2.53 \%$ of population think that Indian government should come up for stringent laws against branded medication. Also $3.53 \%$ population think that there should be a training program to increase awareness regarding generic drugs among doctors and patients.
Around $3.92 \%$ agreed that Indians should use more generic drugs and $4.40 \%$ believed that there should be a store for generic drugs in every hospital. When questions regarding manufacturing quality of the drug were asked around $4.34 \%$ stated that brand name drug are often manufactured in modern facilities and generic drugs in substandard facilities. Regarding safety of the generic drugs $4.08 \%$ stated that generic drugs cause more side effect as compared to branded drugs as shown in Table 3.

Table 2: Knowledge score of the participants.

\begin{tabular}{|lcc|}
\hline Questions & N & Mean \pm SD \\
\hline $\begin{array}{l}\text { Cost effectiveness of generic } \\
\text { drugs }\end{array}$ & 500 & $3.21 \pm 8.822$ \\
\hline $\begin{array}{l}\text { Medicines longer in the } \\
\text { market are more safer }\end{array}$ & 500 & $3.34 \pm 1.436$ \\
\hline $\begin{array}{l}\text { Generic drugs are less } \\
\text { expensive }\end{array}$ & 500 & $3.67 \pm 1.306$ \\
\hline Effectiveness of generic drugs & 500 & $3.01 \pm 1.605$ \\
\hline Total knowledge score & 500 & $17.23 \pm 3.620$ \\
\hline
\end{tabular}

Table 3: Attitude score of the participants.

\begin{tabular}{|lcc|}
\hline $\begin{array}{l}\text { Questions } \\
\text { Like to use generic drugs } \\
\text { more }\end{array}$ & 500 & $3.30 \pm 1.418$ \\
\hline $\begin{array}{l}\text { Need to switch from branded } \\
\text { to generic drugs }\end{array}$ & 500 & $3.97 \pm 1.340$ \\
\hline $\begin{array}{l}\text { Indian government should } \\
\text { come up for stringent laws } \\
\text { against branded medication }\end{array}$ & 500 & $2.53 \pm 1.486$ \\
\hline $\begin{array}{l}\text { Training program should be } \\
\text { conducted to increase } \\
\text { awareness regarding generic } \\
\text { drugs. }\end{array}$ & 500 & $3.53 \pm 1.532$ \\
\hline $\begin{array}{l}\text { Indians should use more } \\
\text { generic drugs }\end{array}$ & 500 & $3.92 \pm 1.432$ \\
\hline $\begin{array}{l}\text { Generic drugs side cause } \\
\text { more side effect than branded } \\
\text { drugs }\end{array}$ & 500 & $4.08 \pm 1.311$ \\
\hline $\begin{array}{l}\text { Generic drug is of a better } \\
\text { value than a brand name drug }\end{array}$ & 500 & $4.13 \pm 1.291$ \\
\hline $\begin{array}{l}\text { Need for generic store in } \\
\text { every hospital }\end{array}$ & 500 & $4.40 \pm 1.139$ \\
\hline $\begin{array}{l}\text { Brand name drugs are made } \\
\text { in modern manufacturing } \\
\text { facilities and generic drugs } \\
\text { made in substandard facilities }\end{array}$ & 500 & $4.34 \pm 1.225$ \\
\hline \begin{tabular}{l} 
Total attitude score \\
\hline
\end{tabular} & 500 & $40.65 \pm 6.448$ \\
\hline
\end{tabular}

The mean practice score was $7.96 \pm 2.350 .7 .96 \%$ reported about that they use generic drugs. Also, $3.93 \%$ stated that they would rather take a generic drug than a branded drug if it is less expensive and $4.03 \%$ stated that would take generics if it was free as shown in Table 4. The total score was found to be 65.84 . 
In the present study it was found that demographic parameters such as occupation $(\mathrm{p}=0.623)$, income $(p=0.27)$, education $(p=0.74)$ and socioeconomic status $(p=0.272)$ were significantly not correlated with knowledge of the participants regarding generic drugs. However, these parameters were significantly correlated with attitude of the participants. It was also found that occupation $(\mathrm{p}=0.00)$, income $(\mathrm{p}=0.47)$, educational status $(\mathrm{p}=0.61)$, socioeconomic status $(\mathrm{p}=0.000)$ were significantly correlated with their practice of generic drugs.

It was highlighted that there is a significant correlation between knowledge of the participants and attitude regarding their usage of generic drugs $(p=0.00)$. However their knowledge and practice for the same was significantly not correlated $(\mathrm{p}=0.123)$ as shown in Table 5.
It was highlighted that there is a significant correlation between knowledge of the participants and attitude regarding their usage of generic drugs $(p=0.00)$. However their knowledge and practice for the same was significantly not correlated $(\mathrm{p}=0.123)$ as shown in Table 5.

Table 4: Practice score of the participants.

\begin{tabular}{|c|c|c|}
\hline Questions & $\mathbf{N}$ & Mean \pm SD \\
\hline $\begin{array}{l}\text { Participants would use } \\
\text { generic drugs if it is less } \\
\text { expensive than branded } \\
\text { drugs }\end{array}$ & 500 & $3.93 \pm 1.499$ \\
\hline $\begin{array}{l}\text { Participants would use } \\
\text { generic drugs if given for } \\
\text { free }\end{array}$ & 500 & $4.03 \pm 1.372$ \\
\hline Total practice score & 500 & $7.96 \pm 2.350$ \\
\hline
\end{tabular}

Table 5: Correlations between knowledge, attitude and practice of the participants regarding generic drugs using Pearson correlation.

\begin{tabular}{|lllll|}
\hline \multirow{4}{*}{ Knowledge score } & \multicolumn{1}{c}{ Knowledge score } & Attitude score & Practice score \\
& Pearson correlation & 1 & $0.293^{* *}$ & 0.069 \\
\cline { 2 - 5 } & Sig. (2-tailed) & & 0.0001 & 0.123 \\
\cline { 2 - 5 } Attitude score & $\mathrm{N}$ & 500 & 500 & 500 \\
& Pearson correlation & $.293^{* *}$ & 1 & $0.477^{* *}$ \\
\cline { 2 - 5 } & Sig. (2-tailed) & .000 & 500 & 0.0001 \\
\cline { 2 - 5 } Practice score & $\mathrm{N}$ & 500 & $0.477^{* *}$ & 500 \\
& Pearson correlation & .069 & 0.000 & 1 \\
\cline { 2 - 5 } & Sig. (2-tailed) & .123 & 500 & 500 \\
\hline
\end{tabular}

** Correlation is significant at the 0.01 level (2-tailed).

\section{DISCUSSION}

The purpose of this research was to assess knowledge, attitude and practice regarding use of generic drugs. In this study socioeconomic status of the participants was recorded using Modified Kuppuswamy socio-economic status scale 2018 as this scale incorporates recording of parameters such as occupation, education and income of the participants and it is found to be highly reliable.

The results in the survey concluded that only $17.23 \pm 3.620$ of the participants were aware about generic drugs. The knowledge regarding these drugs was found equivalent in both males and females. The safety of generic drugs was also questionable by majority as only $3.4 \%$ believe that generic drugs are safer than branded drugs. Also, $3.67 \%$ know that generic drugs are less expensive whereas only $3.01 \%$ of them agree that generic drugs are more effective than brand name drugs.

These results depict negative perception and lack of knowledge related to generic drugs. On correlating the knowledge of the participants with their demographic variables it depicts that majority of population belonging to higher educational status, higher occupation, high income strata and upper socioeconomic class still lack information regarding generic drugs. This creates an alarming situation and increased need of training campaigns by the Indian government to increase awareness.

Participants were asked about their attitude regarding usage of generic drugs out of which nearly $40.65 \pm 6.448$ of the participants showed positive attitude. Only $3.30 \%$ showed their interest regarding usage of generic drugs and $3.97 \%$ stated that there is a need to switch from branded to generic drugs. Around $2.53 \%$ of the participants said that Indian government should come up for stringent laws against branded medication. The safety of generic drugs was also questioned out of which $4.08 \%$ stated that generics have more side effect. The participants also had negative attitude regarding manufacturing facilities of generic drugs as $4.34 \%$ reported that generic drugs are made in substandard facilities and branded made in modern facilities. Further only $3.53 \%$ agreed or think that there should be implementation of awareness campaigns 
and training programs. This result was found in concordance with the knowledge of the participants. It was found that participants belonging to higher occupation, higher education, higher income strata, and upper socioeconomic class had better attitude related to quality, effectiveness, and efficacy of generic drugs. ${ }^{8}$

Participants were also questioned to assess their practice regarding generic drugs. Only $7.96 \pm 2.350$ of participants stated to practice generic drugs. Related to cost effectiveness of these drugs nearly $3.93 \%$ stated that they will only use generics if they found them cheaper or given for free. Also only $4.03 \%$ reported that they save more money per month by using generic drugs. It was also noted that participants belonging to high occupation, higher income strata, and upper socioeconomic class are more in favor of practicing generic drugs. However, among higher education participants such results were not found. There has been studies conducted to assess the cost effectiveness of generic drugs and the result obtained was similar to the present study. ${ }^{9}$

In this study knowledge and attitude related to generic drugs was found to be significantly correlated $(\mathrm{p}=0.0001)$ whereas it was not significant with practice of these drugs $(p=0.123)$. It may be concluded that participants with significant knowledge still don't practice generic drugs depicting their reliability on branded drugs and less influence from the physicians. This survey highlights the necessity of implementing training, and/or incentives that would improve the knowledge, attitude and practice and therefore the adherence to generic medicines, with the reduction of the pharmaceutical expense in the country and better service level to the patients.

\section{CONCLUSION}

From this survey it can be concluded that there is severe lack of knowledge regarding generic drugs in majority of participants. It was seen that people with knowledge related to these drugs do like to use these drugs but they still don't practice them regularly. Thus, in order to detect needs of information about generic medicines not covered in the patients, it is interesting to highlight the data that reflect a negative perception about them.
Funding: No funding sources Conflict of interest: None declared

Ethical approval: The study was approved by the Institutional Ethics Committee

\section{REFERENCES}

1. Andersson K, Bergström G, Petzold MG, Carlsten A. Impact of a generic substitution reform on patients' and society's expenditure for pharmaceuticals. Health Policy. 2007;81:376-84.

2. National Association of Pharmaceutical Manufacturers (NAPM). The generic pharmaceutical market in South Africa: At the cross roads? J Generic Med. 2009;6:377-44.

3. King DR, Kanavos P. Encouraging the use of generic medicines: implications for transition economics. Croat Med J. 2002;43(4):462-9

4. Chua GN, Hassali AM, Shafie AA, Awaisu A. A survey exploring knowledge and perceptions of general practitioners towards the use of generic medicines in the northern state of Malaysia. Health Policy. 2010;95:229-5.

5. Bakthavathsalam G. Generic drugs: Cost effective alternative to branded drugs. Health Adm. 2009;9(1):16-9.

6. Olusola AM, Olubukola OO, Emeka OH, Lilian AE. Equivalence of two generic brands of amlodipine besylate under biowaiver conditions. Int $\mathrm{J}$ Pharmacy Pharm Sci. 2012;4(2):265-8.

7. Bulsara C, McKenzie A, Sanfilippo F, Holman CD, Emery JE. 'Not the full Monty': A qualitative study of seniors' perceptions of generic medicines in Western Australia. Aust J Prim Health. 2010;16:240-5.

8. Akici A, Aydin V, Mollahaliloglu S, Ozgulcu S, Alkan A. Evaluation of the attitudes of specialist and family physicians regarding rational drug selection. North Clin Istanb. 2009;5(3):199-206.

9. Cheung WY, Kornelsen EA, Mittmann N. The economic impact of the transition from branded to generic oncology drugs. Curr Oncol. 2019;26(2):8993.

Cite this article as: Kumar G, Garg A, Dhillon JK, Eranhikkal A, Smitha M. Knowledge, attitude and practice regarding generic drugs and branded drugs: a cross sectional study. Int J Basic Clin Pharmacol 2019;8:2069-73. 